\title{
Genome-wide loss of heterozygosity and copy number alteration in esophageal squamous cell carcinoma using the Affymetrix GeneChip Mapping 10 K array
} $\mathrm{Nan} \mathrm{Hu}^{\dagger 1}$, Chaoyu Wang ${ }^{\dagger 1}$, Ying $\mathrm{Hu}^{2}$, Howard $\mathrm{H}$ Yang${ }^{2}$, Li-Hui Kong ${ }^{3}$, Ning Lu${ }^{4}$, Hua Su${ }^{1}$, Quan-Hong Wang ${ }^{3}$, Alisa M Goldstein ${ }^{1}$, Kenneth H Buetow ${ }^{2}$, Michael R Emmert-Buck ${ }^{5}$, Philip R Taylor*1 and Maxwell P Lee*2

Address: ${ }^{1}$ Genetic Epidemiology Branch, Division of Cancer Epidemiology and Genetics, NCI, USA, ${ }^{2}$ Laboratory of Population Genetics, Center for Cancer Research, NCI, USA, ${ }^{3}$ Shanxi Cancer Hospital, Taiyuan, Shanxi 030013, PR China, ${ }^{4}$ Cancer Institute \& Hospital, Chinese Academy of Medical Sciences, Beijing, 100021, PR China and ${ }^{5}$ Laboratory of Pathology, Center for Cancer Research, NCI, USA

Email: NanHu -nh38k@nih.gov; ChaoyuWang -wangc@mail.nih.gov; Ying Hu -yhu@mail.nih.gov; Howard H Yang - hy43h@nih.gov; LiHui Kong - han_xiaoyou@yahoo.com.cn; Ning Lu - nlu03@126.com; Hua Su - hs98@georgetown.edu; Quan-

Hong Wang - zhongmeiketi@yahoo.com.cn; Alisa M Goldstein - ag29o@nih.gov; Kenneth H Buetow - buetowke@mail.nih.gov; Michael R Emmert-Buck - buckm@mail.nih.gov; Philip R Taylor* - ptaylor@mail.nih.gov; Maxwell P Lee* - maxlee@mail.nih.gov

* Corresponding authors †Equal contributors

Published: 29 November 2006

BMC Genomics 2006, 7:299 doi:10.1186/147|-2164-7-299
Received: 03 August 2006

Accepted: 29 November 2006

This article is available from: http://www.biomedcentral.com/I47I-2/64/7/299

(C) 2006 Hu et al; licensee BioMed Central Ltd.

This is an Open Access article distributed under the terms of the Creative Commons Attribution License (http://creativecommons.org/licenses/by/2.0), which permits unrestricted use, distribution, and reproduction in any medium, provided the original work is properly cited.

\begin{abstract}
Background: Esophageal squamous cell carcinoma (ESCC) is a common malignancy worldwide. Comprehensive genomic characterization of ESCC will further our understanding of the carcinogenesis process in this disease.

Results: Genome-wide detection of chromosomal changes was performed using the Affymetrix GeneChip $10 \mathrm{~K}$ single nucleotide polymorphism (SNP) array, including loss of heterozygosity (LOH) and copy number alterations (CNA), for 26 pairs of matched germ-line and micro-dissected tumor DNA samples. LOH regions were identified by two methods - using Affymetrix's genotype call software and using Affymetrix's copy number alteration tool (CNAT) software - and both approaches yielded similar results. Non-random LOH regions were found on 10 chromosomal arms (in decreasing order of frequency: 17p, 9p, 9q, 13q, 17q, 4q, 4p, 3p, 15q, and 5q), including 20 novel $\mathrm{LOH}$ regions (I0 kb to $4.26 \mathrm{Mb}$ ). Fifteen CNA-loss regions (200 kb to $4.3 \mathrm{Mb}$ ) and $36 \mathrm{CNA}$ gain regions (200 kb to $9.3 \mathrm{Mb}$ ) were also identified.

Conclusion: These studies demonstrate that the Affymetrix $10 \mathrm{~K}$ SNP chip is a valid platform to integrate analyses of $\mathrm{LOH}$ and CNA. The comprehensive knowledge gained from this analysis will enable improved strategies to prevent, diagnose, and treat ESCC.
\end{abstract}




\section{Background}

Genetic instabilities are characteristic of most human cancers. Genome-wide detection of chromosomal changes, including loss of heterozygosity ( $\mathrm{LOH}$ ) and copy number alterations (CNA), either gain or loss, are the focus of substantial attention in cancer research. $\mathrm{LOH}$ is frequently observed in a variety of human cancers, and regions with frequent LOH may contain tumor suppressor genes. In addition, LOH may associate with the regions affected by haplo-insufficiency of a group of genes. Thus, detection of LOH will likely remain a cornerstone for predicting tumor aggressiveness for many human tumors [1]. Recently, the discovery of large-scale genome-wide copy number variation has stimulated interest in elucidating the role of CNA in the development of malignancy. The $10 \mathrm{~K}$ single nucleotide polymorphism (SNP) array (GeneChip Mapping 10 $\mathrm{K}$ array, Affymetrix) offers a high-resolution genomic approach to screen chromosomal alterations systematically. Several studies on allelic imbalance or loss in cancers and cancer cell lines using the $10 \mathrm{~K} \mathrm{SNP}$ array have been published [2-12].

Esophageal squamous cell carcinoma (ESCC) is a common malignancy worldwide and one of the most common malignancies in the Chinese population. There is great geographic variation in the occurrence of this tumor in China, including exceptionally high-risk areas such as Shanxi Province in north central China where some of the highest esophageal cancer rates in the world occur. The standardized incidence rate for esophageal cancer in Shanxi Province is above 100/100,000 person-years, although it appears that both incidence and mortality rates have begun to decline in the past 10 years $[13,14]$. Within the high-risk regions in China, there is a strong tendency toward familial aggregation, suggesting that genetic susceptibility, in conjunction with environmental exposures, plays a role in the etiology of ESCC. In the past several years, we have tried to identify susceptibility genes and biomarkers that can be used to screen high-risk populations in north central China for ESCC [15-22]. A previous study examined 366 microsatellite markers in a $10 \mathrm{cM}$ density genome-wide scan in 11 ESCC patients, and identified 14 chromosome arms with high-frequency LOH [15]. However, we were unable to further narrow these LOH regions using microsatellite markers due to their low density. Higher density markers are necessary for positional cloning of tumor suppressor genes in $\mathrm{LOH}$ regions.

In the present study we established a high-resolution chromosomal instability profile for ESCC by examining germ-line DNA and matched micro-dissected tumor DNA with a $10 \mathrm{~K} \mathrm{SNP}$ array to determine both LOH and CNA. We also evaluated whether a pool of normal control samples could be used as the normal referent in an LOH study with the $10 \mathrm{~K}$ SNP chip instead of matched germ-line DNA.

\section{Results and discussion LOH by patient and chromosomal arms}

In the present study, 26 ESCC patients with blood-derived germ-line DNA and matched micro-dissected tumor DNA were investigated using $10 \mathrm{~K} \mathrm{SNP}$ arrays. The characteristics of these patients are shown in Table 1. The average signal detection rate was higher in germ-line DNA (99\%) than that in micro-dissected tumor DNA (79\%). Based on NCBI Build 35.1, we summarized characteristics of 11,555 SNPs and mapped them to chromosomes and genes. We first generated a genotyping profile for each patient based on a comparison of the germ-line DNA genotypes to those from the matched micro-dissected tumor DNA. The patients' LOH frequencies, shown in Table 1, ranged from $19 \%$ to $95 \%$, and averaged $29 \%$. LOH in four cases (SHE0832, SHE0864, SHE1264, and SHE1490) was performed using DNA from micro-dissected adjacent normal tissue in addition to blood-derived germ-line DNA to see if this affected results, but findings were very similar with both of these two sources of DNA (Table 1).

The frequencies of $\mathrm{LOH}$ on each chromosomal arm are shown in Table 2. Non-random LOH was observed on 10 chromosomal arms, including 17p (76\%), 9p (72\%), 9q (72\%), 13q (68\%), 17q (66\%), 4q (65\%), 4p (60\%), 3p $(58 \%), 15 q(57 \%)$, and $5 q(52 \%)$. Our previous microsatellite marker-based genome-wide LOH scan in 11 ESCC patients with a positive family history of upper gastrointestinal cancer produced overall $\mathrm{LOH}$ frequencies that were somewhat higher than the patients evaluated in the present study [15]. We can not explain this between-study LOH frequency variation, but there are several noteworthy differences between the studies that likely influenced LOH rates, including: (i) heterozygosity is higher for the microsatellite compared to the SNP markers examined ( 75\% versus 30\%); (ii) the total number of markers was much higher in the SNP study than the microsatellite study (11,000 versus 366); and (iii) over twice as many cases were examined in the SNP study (26 versus 11 ). Some results between studies differed (eg, $\mathrm{LOH}$ was $\geq$ $50 \%$ on chromosome $15 \mathrm{q}$ in the SNP but not the microsatellite study; $\mathrm{LOH}$ was $\geq 50 \%$ on $8 \mathrm{p}, 8 \mathrm{q}, 11 \mathrm{p}, 11 \mathrm{q}$ and $18 \mathrm{p}$ in the microsatellite but not the SNP study). Despite differences in study size, approach, and in some of the results, consistently high $\mathrm{LOH}$ frequencies were reported for nine chromosomal arms in both studies (ie, 3p, 4p, $4 q, 5 q, 9 p, 9 q, 13 q, 17 p, 17 q)$. Both studies taken together indicate that $\mathrm{LOH}$ on these nine chromosomal arms are the major events associated with genome-wide instability in ESCC in this high-risk Chinese population. These areas are rich in known tumor suppressor genes and oncogenes, including VHL on 3p; NPCA1 on 4p; KIT, GIST, and PDG- 


\begin{tabular}{|c|c|c|c|c|c|c|c|c|c|c|c|c|c|}
\hline No. & ID & Age/sex & $\begin{array}{l}\text { Tumor } \\
\text { location }\end{array}$ & $\begin{array}{c}\text { Tumor } \\
\text { stage/grade }\end{array}$ & Metastasis & $\begin{array}{c}\text { FH of UGI } \\
\text { cancer (Y/N) }\end{array}$ & $\begin{array}{l}\text { Tobacco } \\
\text { use (Y/N) }\end{array}$ & $\begin{array}{c}\text { Alcohol } \\
\text { use }(\mathbf{Y} / \mathrm{N})\end{array}$ & $\begin{array}{c}\text { Pickled } \\
\text { vegetables (Y/N) }\end{array}$ & $\begin{array}{c}\text { Survival } \\
\text { status }\end{array}$ & $\begin{array}{l}\text { Survival } \\
\text { months }\end{array}$ & $\begin{array}{c}\text { LOH* } \\
\text { (blood DNA reference) }\end{array}$ & $\begin{array}{c}\text { LOH* (normal } \\
\text { esophagus reference) }\end{array}$ \\
\hline 1 & SHE0043 & $72 / M$ & lower & $3 / 11$ & Y & $N$ & $Y$ & $\mathrm{~N}$ & $\mathrm{~N}$ & deceased & 29.6 & 0.951 & \\
\hline 2 & SHEOI33 & $55 / M$ & lower & $\mid / I I I I$ & Y & $Y$ & $Y$ & $\mathrm{~N}$ & $\mathrm{~N}$ & deceased & 36.5 & 0.907 & \\
\hline 3 & SHE0200 & $46 / \mathrm{M}$ & middle & $\mid / I I I$ & Y & Y & $Y$ & Y & Y & deceased & 45 & 0.875 & \\
\hline 4 & SHE0204 & $51 / M$ & middle & 2/III & $\mathrm{N}$ & Y & $Y$ & $\mathrm{~N}$ & $\mathrm{~N}$ & alive & 64.9 & 0.345 & \\
\hline 5 & SHE0223 & 60/M & middle & 2/III & $\mathrm{N}$ & Y & $\mathrm{N}$ & $\mathrm{N}$ & Y & deceased & 34.8 & 0.807 & \\
\hline 6 & SHE0297 & $64 / M$ & middle & 4/III & $Y$ & $Y$ & Y & $Y$ & $\mathrm{~N}$ & deceased & 6.9 & 0.596 & \\
\hline 7 & SHE0362 & $52 / \mathrm{M}$ & middle & $2 / 1$ & $Y$ & Y & $Y$ & $Y$ & $Y$ & alive & 58.1 & 0.236 & \\
\hline 8 & SHE0366 & $46 / \mathrm{M}$ & lower & $3 / 11$ & $Y$ & $\mathrm{~N}$ & $Y$ & $Y$ & $\mathrm{~N}$ & deceased & 26.2 & 0.849 & \\
\hline 9 & SHE0633 & $63 / \mathrm{M}$ & lower & 3/III & $\mathrm{N}$ & Y & $Y$ & $\mathrm{~N}$ & $Y$ & deceased & 26.5 & 0.635 & \\
\hline 10 & SHE0758 & $54 / \mathrm{M}$ & lower & 3/III & $\mathrm{N}$ & $\mathrm{N}$ & $Y$ & $N$ & $\mathrm{~N}$ & deceased & 6.6 & 0.267 & \\
\hline 11 & SHE0782 & $49 / F$ & middle & 2/II & $Y$ & Y & $\mathrm{N}$ & $N$ & $Y$ & deceased & 29.6 & 0.211 & \\
\hline 12 & SHE0816 & $58 / \mathrm{M}$ & upper & 3/III & $\mathrm{N}$ & $Y$ & $Y$ & Y & Y & deceased & 30.7 & 0.262 & \\
\hline 13 & SHE0832 & $52 / \mathrm{M}$ & middle & $3 / 11$ & $\mathrm{~N}$ & Y & $Y$ & Y & Y & alive & 42.5 & 0.215 & 0.219 \\
\hline 14 & SHE0848 & $62 / F$ & middle & $3 / 11$ & $\mathrm{~N}$ & $\mathrm{~N}$ & $Y$ & $\mathrm{~N}$ & Y & alive & 39.0 & 0.384 & \\
\hline 15 & SHE0863 & $51 / M$ & upper & $3 / 11$ & $\mathrm{~N}$ & $\mathrm{~N}$ & $Y$ & Y & Y & alive & 39.4 & 0.567 & \\
\hline 16 & SHE0864 & $55 / M$ & middle & $4 / 11$ & Y & $\mathrm{N}$ & $Y$ & Y & Y & deceased & 10.8 & 0.204 & 0.197 \\
\hline 17 & SHE0878 & $67 / M$ & lower & $3 / 1$ & $\mathrm{~N}$ & $Y$ & $Y$ & $Y$ & $Y$ & deceased & 2.2 & 0.806 & \\
\hline 18 & SHE0905 & $58 / \mathrm{F}$ & middle & $3 / 11$ & $N$ & $N$ & $N$ & $N$ & Y & alive & 35.5 & 0.188 & \\
\hline 19 & SHE0912 & $45 / \mathrm{M}$ & middle & $3 / 11$ & $Y$ & $\mathrm{~N}$ & $Y$ & $\mathrm{~N}$ & Y & deceased & 31.2 & 0.747 & \\
\hline 20 & SHE092I & $64 / \mathrm{M}$ & lower & 3/III & $\mathrm{N}$ & Y & $Y$ & $Y$ & Y & deceased & 13.2 & 0.246 & \\
\hline 21 & SHEI255 & $61 / \mathrm{M}$ & middle & 2/II & $Y$ & Y & $\mathrm{N}$ & $Y$ & Y & deceased & 20.0 & 0.567 & \\
\hline 22 & SHEI 264 & $68 / \mathrm{M}$ & middle & $3 / 11$ & $Y$ & $\mathrm{~N}$ & $Y$ & $Y$ & $\mathrm{~N}$ & deceased & 16.2 & 0.27 & 0.267 \\
\hline 23 & SHEI30I & $64 / \mathrm{M}$ & middle & $3 / 11$ & $Y$ & $Y$ & $\mathrm{~N}$ & $N$ & $Y$ & alive & 23.2 & 0.233 & \\
\hline 24 & SHEI3।O & $55 / F$ & middle & 2/II & Y & $N$ & $\mathrm{~N}$ & $\mathrm{~N}$ & $Y$ & unknown & - & 0.593 & \\
\hline 25 & SHEI 408 & $63 / \mathrm{M}$ & middle & $3 / 11$ & $\mathrm{~N}$ & $\mathrm{~N}$ & $Y$ & $Y$ & $\mathrm{~N}$ & deceased & 23.3 & 0.224 & \\
\hline 26 & SHEI 490 & $52 / \mathrm{M}$ & middle & 3/11 & $\mathrm{N}$ & $\mathrm{N}$ & $Y$ & $Y$ & $Y$ & alive & 20.0 & 0.3 & 0.287 \\
\hline
\end{tabular}


FRA on $4 \mathrm{q} ; A P C$ and MCC on $5 \mathrm{q} ; C D K N 2 A$ and CDKN2B on 9p; BRCA2 and Rb1 on $13 \mathrm{q}$; TP53 on $17 \mathrm{p}$; and BRCA1, TOC, and NF1 on $17 \mathrm{q}$.

\section{LOH regions}

When we used the conservative, traditional approach to $\mathrm{LOH}$ in LOH/Model A, we detected $20 \mathrm{LOH}$ regions encompassing a total of 125 SNPs. As shown in Table 3, these $20 \mathrm{LOH}$ regions are located on eight chromosome arms - 13q (four regions), 3p (two regions), 4q (three regions), 9p (two regions), 9q (three regions), 17p (three regions), $17 \mathrm{q}$ (two regions), and $4 \mathrm{p}$ (one region). The size of these $\mathrm{LOH}$ regions ranged from $10 \mathrm{~kb}$ to $4.26 \mathrm{Mb}$ (average $1.44 \mathrm{Mb}$ ); genes involved in these deletion regions are shown in Table 3. Among the 125 SNPs in these $20 \mathrm{LOH}$ regions, 46 are located in genes (one in a coding exon, 39 in introns, and six in 3'- or 5'-UTRs), and 79 are located in regions flanking genes (ie, within $1 \mathrm{~kb}$ ). One SNP (rs781852) is located in the coding region of gene ZZEF1 (Zinc finger, ZZ-type with EF-hand domain 1) on chromosome 17p13.2. Allele A for this SNP encodes an amino acid proline (Pro) and the allele $\mathrm{B}$ encodes amino acid leucine (Leu). Eight of 10 heterozygous cases (Pro/Leu) showed $\mathrm{LOH}(80 \%)$, including five cases that lost allele B and three cases that lost allele A. The 46 SNPs that are located within genes map to 32 genes and include four SNPs in the introns of ZNF618, and two SNPs each in the introns of ITPR1, FLJ14834, LHFP, ITGAE, MYH3 and MYOCD. Some of these 20 deletion regions have been previously identified by our lab and others $[17,22]$. How- ever, the current study provides far greater precision in locating $\mathrm{LOH}$ regions (10 kb-4.26 Mb as opposed to 10 $\mathrm{cM}$, which corresponds to 5-10 Mb). As expected, using a less conservative definition for $\mathrm{LOH}$, LOH/Model B detected more regions (and SNPs) than our approach in LOH/Model A - 72 LOH regions containing 2,916 SNPs. The distribution of deletion regions and details from this model are shown in Table 4 and Additional Table 1 (in additional file 1).

Our cLOH data in CLOH/Model A identified only three significant cLOH regions. These included one on 13q12q13 and two on 13q13, and encompassed a total of 30 SNPs. The sizes of these cLOH regions are $1.9 \mathrm{Mb}, 0.4 \mathrm{Mb}$, and $0.2 \mathrm{Mb}$, respectively (average $0.83 \mathrm{Mb}$ ) (Table 5). The less conservative cLOH/Model B highlighted $64 \mathrm{cLOH}$ regions with 2,128 SNPs; details are shown in Table 6 and Additional Table 2 (in additional file 1).

Examples of the whole genome profiles for regions on chromosome arms 9p/q, 13q, and 17p are shown in Figures $1,2,3$.

\section{Comparison of $\mathrm{LOH}$ and $\mathrm{cLOH}$ regions}

Our conservative LOH/Model A detected $20 \mathrm{LOH}$ regions including 125 SNPs, but our conservative cLOH/Model A detected only three $\mathrm{LOH}$ regions containing 30 SNPs. The detection of only three $\mathrm{LOH}$ regions by CLOH/Model A is not unexpected since identifying an LOH region in a sample requires the presence of multiple homozygous SNPs

Table 2: LOH distribution by chromosomal arm

\begin{tabular}{|c|c|c|c|}
\hline Chr arm & LOH in ESCC $(n=26)$ & Chr arm & LOH in ESCC $(n=26)$ \\
\hline Ip & $0.282(563 / 1998)$ & $I I p$ & $0.393(444 / 1$ I 30$)$ \\
\hline $\mathrm{Iq}$ & $0.211(377 / 1787)$ & $11 \mathrm{q}$ & $0.372(591 / 1590)$ \\
\hline $2 p$ & $0.301(56 I / I 86 I)$ & $12 p$ & $0.259(149 / 576)$ \\
\hline $2 q$ & $0.331(782 / 2363)$ & $12 q$ & $0.265(496 / 1874)$ \\
\hline $3 p$ & $0.576(955 / 1658)$ & $13 q$ & $0.682(1300 / 1907)$ \\
\hline $3 q$ & 0.287 (482/1677) & $14 q$ & $0.46 I(846 / 1836)$ \\
\hline $4 p$ & $0.602(509 / 846)$ & $15 q$ & $0.568(845 / 1487)$ \\
\hline $4 q$ & $0.645(1424 / 2208)$ & $16 p$ & $0.285(148 / 520)$ \\
\hline $5 p$ & $0.316(286 / 906)$ & $16 q$ & $0.338(213 / 631)$ \\
\hline $5 q$ & $0.516(1321 / 2560)$ & $17 p$ & $0.755(246 / 326)$ \\
\hline $6 p$ & $0.445(545 / 1226)$ & $17 q$ & $0.673(450 / 669)$ \\
\hline $6 q$ & $0.4 I 7(98 I / 235 I)$ & $18 p$ & $0.409(142 / 347)$ \\
\hline $7 p$ & $0.331(398 / I 201)$ & $18 q$ & $0.481(5 / 3 / 1067)$ \\
\hline $7 q$ & 0.348 (539/I55I) & $19 p$ & $0.389(58 / 149)$ \\
\hline $8 p$ & $0.433(331 / 764)$ & $19 q$ & $0.442(184 / 416)$ \\
\hline $8 q$ & 0.313 (550/I759) & $20 p$ & $0.318(208 / 655)$ \\
\hline $9 p$ & $0.7 / 7$ (867/I209) & $20 q$ & $0.335(178 / 532)$ \\
\hline $9 q$ & 0.715 (7I4/999) & $2 \mathrm{lq}$ & $0.391(339 / 866)$ \\
\hline $10 p$ & 0.367 (314/855) & $22 q$ & $0.349(157 / 450)$ \\
\hline $10 q$ & $0.366(694 / 1897)$ & & \\
\hline
\end{tabular}

Average $\mathrm{LOH}=\mathbf{0 . 4 2 5}$ 
Table 3: Deletion regions from the conservative "LOH/Model A"

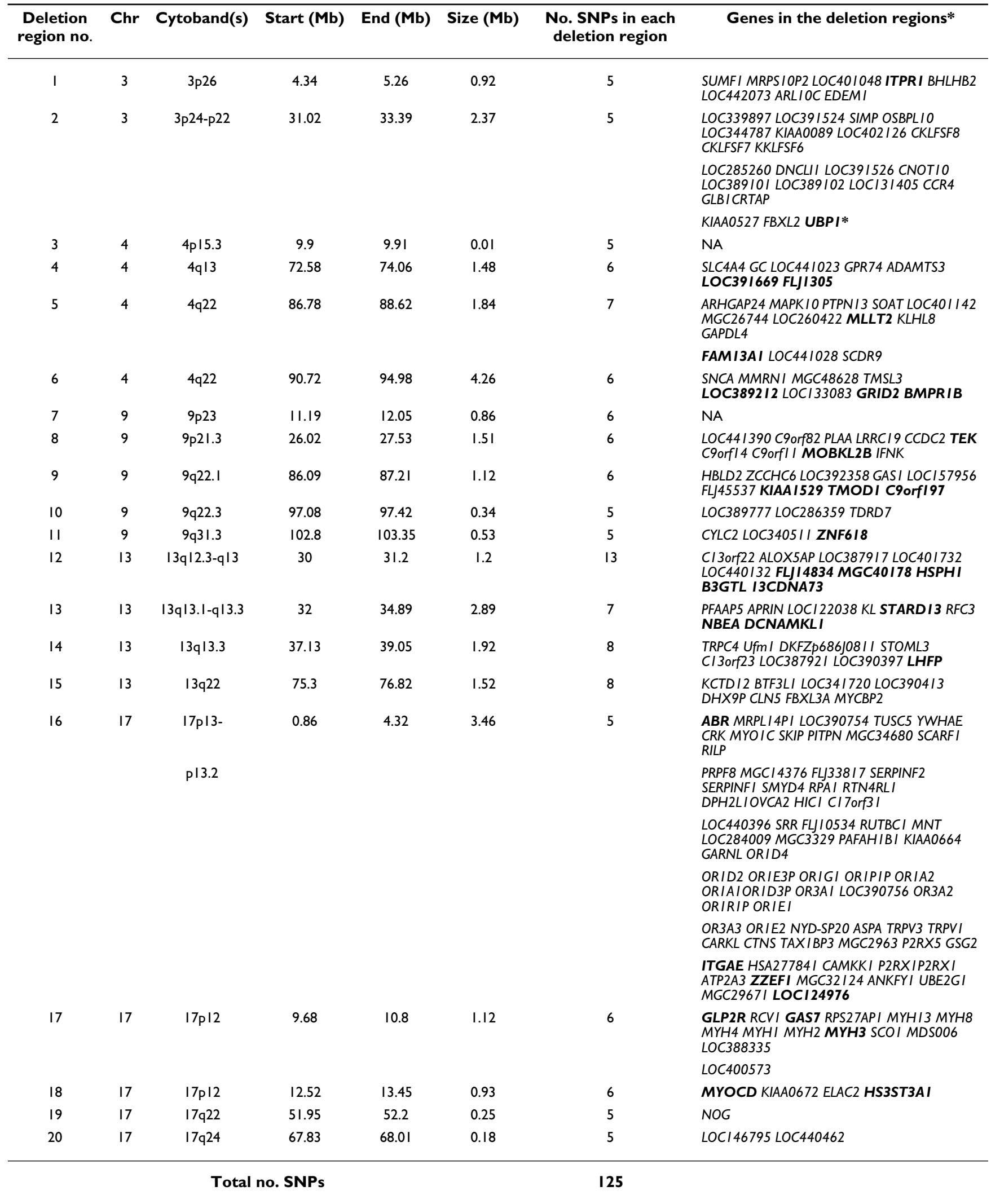

*SNPs in genes (exons, introns, or 3'- or 5'-UTRs) are shown in bold. 
Table 4: Deletion regions from the less conservative "LOH/Model B"

\begin{tabular}{|c|c|c|c|}
\hline Chr arm & $\begin{array}{l}\text { No. deletion regions } \\
\text { in each chr arm }\end{array}$ & Cytoband(s) & $\begin{array}{l}\text { Total no. SNPs } \\
\text { in each chr arm }\end{array}$ \\
\hline $2 q$ & 1 & $2 q 35$ & 6 \\
\hline $3 p$ & 6 & 3p26-p25 3p25-p24.3 3p24 3p24-p|4 3p|4-pl3 3pl3 & 293 \\
\hline $4 p$ & 4 & 4pI6-pl5.3 4pI5.34pI5.I-pI3 4pI2-q12 & 150 \\
\hline $4 q$ & 5 & $4 q 214 q 21.2-q 224 q 22-q 31.24 q 31.2-q 344 q 34-q 35$ & 486 \\
\hline $5 q$ & 8 & $5 q|1.2-q| 55 q \mid 5$ 5q2। 5q22 5q23 (2) 5q32-q34 5q34-q35 & 357 \\
\hline $6 p$ & 5 & 6p24-p23 6p22.3 6p22.2-p21.2 6p21.2 6p1।.2-q12 & 75 \\
\hline $6 q$ & 1 & $6 q 15$ & 21 \\
\hline $8 p$ & 4 & $8 p 23.28 p 22(3)$ & 32 \\
\hline $9 p / q$ & 3 & $9 p 24.39 p 24.3-p 229 p 22-q 33$ & 507 \\
\hline $10 p$ & 1 & $10 p|2.1-p| 1.2$ & 5 \\
\hline$I I p$ & 1 & IIpI5.2 & 6 \\
\hline $\mathrm{IIq}$ & 2 & I Iq23 I Iq24 & 20 \\
\hline $13 q$ & 4 & $|3 q| 2.2-q 3|$.$| |3q31.I 13q32.I |3q32.I-q34$ & 391 \\
\hline $14 q$ & 10 & $|4 q||.2-q| 2|4 q| 2$ (2) |4q2| (3) |4q23 (2) |4q23-q24.2 |4q24.3 & 138 \\
\hline $15 q$ & 10 & 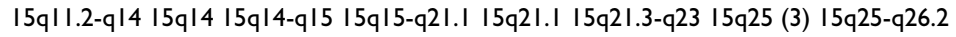 & 190 \\
\hline $17 p / q$ & I & $17 p 13-q 25$ & 174 \\
\hline $18 q$ & 4 & |8q21.1-q21.2 18q21.2 18q22 (2) & 47 \\
\hline $21 \mathrm{q}$ & 1 & $21 q 22.1$ & 10 \\
\hline $22 q$ & 1 & $22 q 12.1-q \mid 2$ & 8 \\
\hline $\begin{array}{l}\text { Total no. } \\
\text { deletion regions }\end{array}$ & 72 & Total no. SNPs & 2916 \\
\hline
\end{tabular}

Table 5: Deletion regions from the conservative "cLOH/Model A"

\begin{tabular}{|c|c|c|c|c|c|c|c|}
\hline $\begin{array}{l}\text { Deletion } \\
\text { region no. }\end{array}$ & Cytoband & Start (Mb) & End (Mb) & Size (Mb) & $\begin{array}{l}\text { No. SNPs in each } \\
\text { deletion region }\end{array}$ & SNP list* & Gene list \\
\hline \multirow[t]{4}{*}{ I } & $|3 q| 2-q \mid 3$ & 27.4 & 29.3 & 1.9 & 15 & $\begin{array}{l}\text { rs720661 } \\
\text { rs748253 } \\
\text { rs } 952648 \\
\text { rs2987346 } \\
\text { rs } 1414357 \\
\text { rs2388092 }\end{array}$ & LOC440I29 CDX2 FLT3 PAN3 \\
\hline & & & & & & $\begin{array}{c}\text { rs2388093 } \\
\text { rs2388094 } \\
\text { rs1986785 } \\
\text { rs719199 } \\
\text { rs159050। } \\
\text { rs724946 }\end{array}$ & FLTI LOC34I 784 CI 3orfI 2 LOC283537 \\
\hline & & & & & & $\begin{array}{c}\text { rs2388094 } \\
\text { rs1986785 } \\
\text { rs719199 } \\
\text { rs159050। } \\
\text { rs724946 } \\
\text { rs } 1409504\end{array}$ & CYP5 IP2 KIAA0774 SLC7AI \\
\hline & & & & & & $\begin{array}{l}\text { rsl409506 } \\
\text { rs } 1073230\end{array}$ & \\
\hline \multirow[t]{2}{*}{2} & $13 q 13$ & 29.6 & 30 & 0.4 & 7 & $\begin{array}{l}\text { rs } 1073229 \\
\text { rs } 1570613 \\
\text { rs } 1331697 \\
\text { rs } 1831549\end{array}$ & KATNALI PRDX2PI UBCH7N2 HMGBI \\
\hline & & & & & & $\begin{array}{c}r s / 343946 * \\
r s / 343945 \\
r s / 854953\end{array}$ & FLJI 4834 \\
\hline \multirow[t]{3}{*}{3} & $|3 q| 3$ & 30.3 & 30.5 & 0.2 & 8 & $\begin{array}{c}\text { rs22007622 } \\
r s 876540 \\
r s 912603 \\
\text { rs2056443 } \\
\text { rs } 13080\end{array}$ & LOC3879I 7 LOC40I 732 LOC440I32 \\
\hline & & & & & & $\begin{array}{l}\text { rsI409379 } \\
\text { rsI328950 } \\
\text { rsI328949 }\end{array}$ & FLJI 4834 MGC40 I 78 B3GTL \\
\hline & \multicolumn{3}{|c|}{ Total no. SNPs } & & 30 & & \\
\hline
\end{tabular}

\footnotetext{
*Italicized SNPs are in genes; bolded SNPs are also found in the 20 deletion regions of the conservative LOH/Model A.
} 
Table 6: Deletion regions from the less conservative "cLOH/Model B"

\begin{tabular}{|c|c|c|c|}
\hline Chr arm & No. regions in each chr arm & Cytoband(s) & $\begin{array}{l}\text { Total no. SNPs in } \\
\text { each chr arm }\end{array}$ \\
\hline $2 q$ & 2 & $2 q 34-q 352 q 35$ & 33 \\
\hline $3 p$ & 7 & $3 p 26$ (2) 3p26-p25 3p21.32-p2.2 & 182 \\
\hline $4 p$ & 4 & $4 p|6.3-p| 5.34 p|5.34 p| 24 p|2-q| 2$ & 100 \\
\hline \multirow[t]{2}{*}{$4 q$} & 14 & $4 q 13$ (2) 4q13-4q22 4q26 4q27 4q27-q28 4q28 & 377 \\
\hline & & $4 q 28-q 324 q 324 q 32-q 334 q 33-q 344 q 34$ & \\
\hline $5 q$ & 15 & $\begin{array}{c}5 q|1.25 q| 1.2-q 125 q 125 q 135 q 13-q 155 q 155 q 15-q 21 \\
5 q 2 \mid-q 225 q 22(2) 5 q 23.15 q 23.1-q 235 q 32-q 345 q 34-q 355 q 35\end{array}$ & 386 \\
\hline $8 p$ & 2 & $8 p 22(2)$ & 13 \\
\hline $9 p$ & 5 & $9 p 24.3-p 239 p 23-p 219 p 21.3-p 21.19 p 21-p 139 p 13-q 22$ & 367 \\
\hline $9 q$ & 2 & $9 q 22.2-q 22.39 q 22.3-q 33$ & 147 \\
\hline \multirow[t]{2}{*}{$13 q$} & 7 & $13 q|2.2-q 14| 3 q|4-q 21.1| 3 q 21.1-q 21.33$ & 365 \\
\hline & & $13 q 21.33-q 31.113 q 31.3-q 32.1$ 13q32.1-q33 13q33 & \\
\hline $17 p$ & 2 & $|7 p| 3-p \mid 2$ |7p|2-q2| & 96 \\
\hline $17 q$ & 3 & I7q21-q22 I7q22-q24 I7q24 & 57 \\
\hline $21 q$ & I & $21 \mathrm{q} 22.2$ & 5 \\
\hline $\begin{array}{l}\text { Total no. } \\
\text { deletion regions }\end{array}$ & 64 & Total no. SNPs & 2128 \\
\hline
\end{tabular}

in a large genomic area and the chance for multiple homozygous SNPs in more than $75 \%$ of the samples is low. The three cLOH regions are all on chromosome 13q12-q13. Eleven SNPs were detected by both conservative $\mathrm{LOH}$ and $\mathrm{CLOH}$ models (LOH/Model A and cLOH/ Model A) (Tables 3 and 5). Five SNPs detected by the conservative cLOH/Model A are located in two genes, FLJ14834 and B3GTL. Due to the relatively small number of $\mathrm{LOH}$ regions defined by $\mathrm{CLOH} /$ Model $\mathrm{A}$, as well as the different definitions of $\mathrm{LOH}$ used in these two approaches, it was not possible to compare the concordance between these two methods.

Our less conservative LOH/Model B and cLOH/Model B were identical except that $\mathrm{LOH} /$ Model B used the matched normal controls while cLOH/Model B used pooled normal control samples. SNPs in the $\mathrm{LOH}$ regions from $\mathrm{LOH} /$ Model B totaled 2,916; 2,128 SNPs were identified in the cLOH regions from cLOH/Model $\mathrm{B}$. The number of SNPs common to both $\mathrm{LOH}$ and cLOH models ( $\mathrm{LOH} /$ Model B and cLOH/Model B) was 1,878, while a total of 1,038 SNPs appeared only in LOH/Model B, 250 SNPs were found only in cLOH/Model B, and 7,834 showed retention in both models. Using $\mathrm{LOH} /$ Model B as a standard, sensitivity/specificity for cLOH/Model B were $64 \%$ and $97 \%$, respectively. The overall Pearson correlation coefficient between these two models was $0.69(P<0.0001)$. Taken together, we detected more SNP loci in LOH/Model $\mathrm{B}$ than $\mathrm{CLOH} /$ Model B, but concordance between the two methods was generally good, suggesting that the use of pooled normal control samples may be acceptable for LOH studies.

\section{CNA regions}

Table 7 shows 15 regions with CNA losses that were detected at $P \leq 10^{-6}$. These include regions on $1 \mathrm{p}, 3 \mathrm{p}, 4 \mathrm{q}$, $5 \mathrm{q}, 9 \mathrm{p}, 10 \mathrm{p}, 11 \mathrm{p}, 11 \mathrm{q}, 13 \mathrm{q}$, and 18q. One-hundred and two SNPs were mapped within these regions (Table 4A). Details of the involved SNPs and genes are shown in Additional Table 3 (in additional file 1). Table 8 shows the 36 regions where significant CNA gains were identified, including eight on chromosomal arm 3q, seven on $8 \mathrm{q}$, three on $7 \mathrm{p}$, two on $5 \mathrm{q}$, two on $14 \mathrm{q}$, and two on $22 \mathrm{q}$ (Additional Table 4 in additional file 1). Examples of whole genome profiles of CNA regions are shown for chromosomes 3, 7, and 8 in Figures 4, 5, 6 .

\section{Comparisons between LOH and CNA}

We obtain both CLOH and CNA data when we use the pooled normal control sample reference in the CNAT software. Thus we can ask the question of whether the cLOH is associated with CNA. Our studies showed that among 2,128 SNPs identified in our less conservative cLOH/ Model B, only 45 (2\%) showed CNA loss and just 14 $(0.7 \%)$ showed CNA gain (Figure 7$)$. This result suggests that CNA accounts for small percent of $\mathrm{LOH}$ events in ESCC. LOH in cancers is commonly caused by one of three different mechanisms. The first and most common cause of LOH is mitotic recombination [3]. This mechanism doesn't change chromosome copy number, and was responsible for $97 \%$ of the $\mathrm{LOH}$ observed in our study. Deletion, the second cause of $\mathrm{LOH}$, should result in copy number loss, and occurred in approximately two percent of LOH in our study. Finally, LOH can result from amplification of one chromosome, which should show copy 

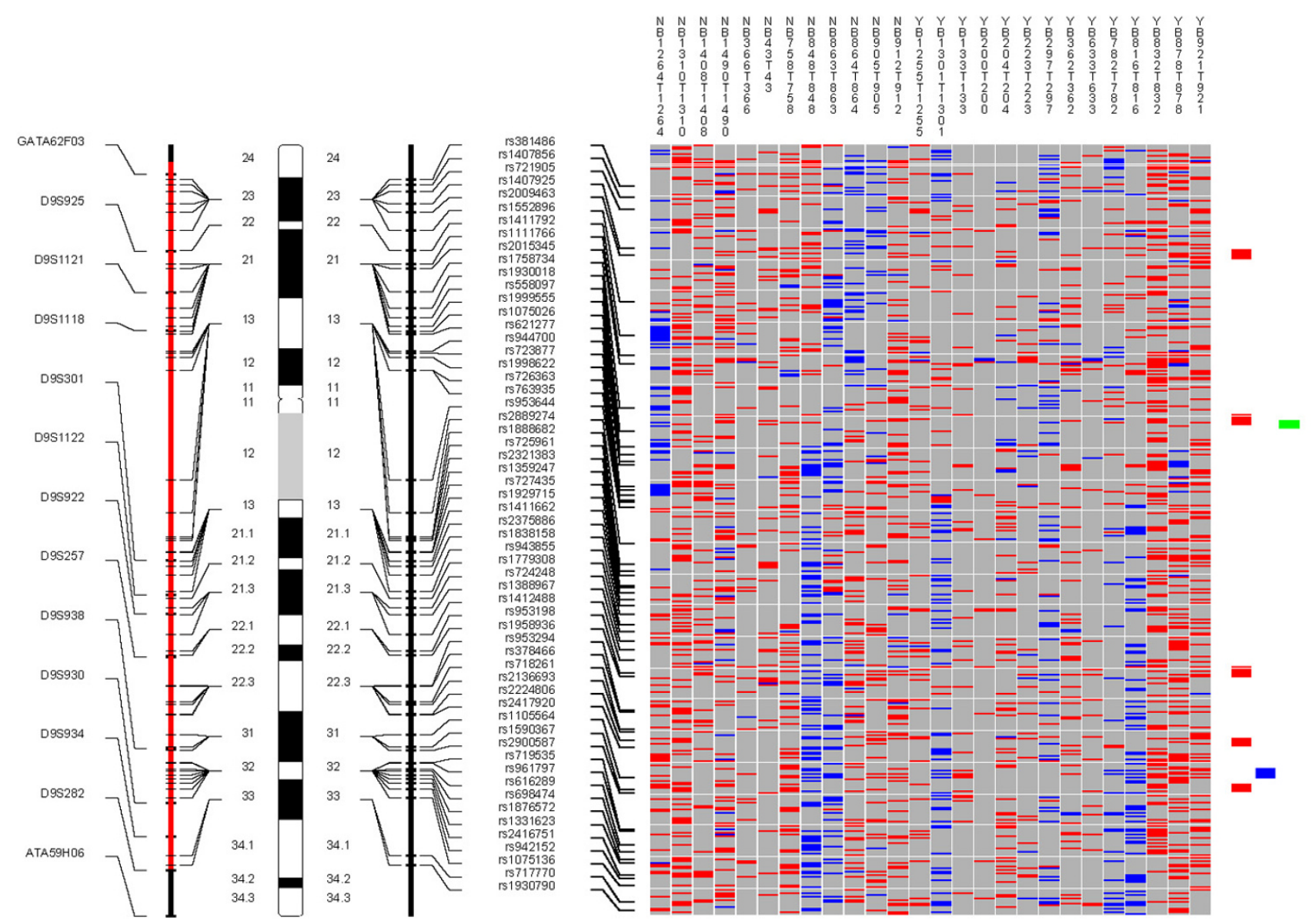

Figure I

Chromosome 9. Each column in the picture represents an individual case and shows genotyping in germ-line DNA and matched micro-dissected tumor; LOH is shown in red, retention in blue, and homozygous or "no call" in grey. B indicates blood DNA and T indicates tumor DNA (from matched, micro-dissected sample). To the left of the picture, columns show (from left to right): microsatellite markers, cartoon of the chromosome, and SNPs examined in the $10 \mathrm{~K}$ SNP chip. To the right of the picture, red bars show deletion regions (as defined from our conservative "LOH/Model A"), blue bars show regions with CNA losses (from CNAT), and green bars show regions with CNA gains (from CNAT).

number gain. This mechanism accounted for less than one percent of LOH in our study. Although chromosomal amplification occurs often, only occasionally do amplification events result in LOH, which correspond to unbalanced amplification of one chromosome. However, some studies have demonstrated concordance between $\mathrm{LOH}$ and CNA. For example, Wong et al found $\mathrm{LOH}$ associated with CNA gain at 6q12-13 in osteosarcoma [5], and Zhao et al found a link between $\mathrm{LOH}$ and CNA gain at 1q22q24.1 and 1q42.13-43 in oral squamous cell carcinoma [8]. These differences might reflect genuine differences between tumor types, the lab analytic methods used, or different operative mechanisms at work.
The genome-wide $\mathrm{LOH}$ and chromosome copy alteration studies described in this paper can also be applied to higher density SNP chips, such as Affymetrix $100 \mathrm{~K}$ and $500 \mathrm{~K}$ SNP chips. The increased SNP density will allow even finer mapping of these genetic changes.

In summary, we performed a genome-wide study of $\mathrm{LOH}$ and CNA in ESCC patients using the Affymetrix $10 \mathrm{~K} \mathrm{SNP}$ chip by comparing matched germ-line and tumor DNA. Our approach allowed us to extensively map both LOH and CNAs in ESCC systematically in a manner that has not heretofore been done, and produced numerous regions, genes, and SNPs that merit future exploration. 

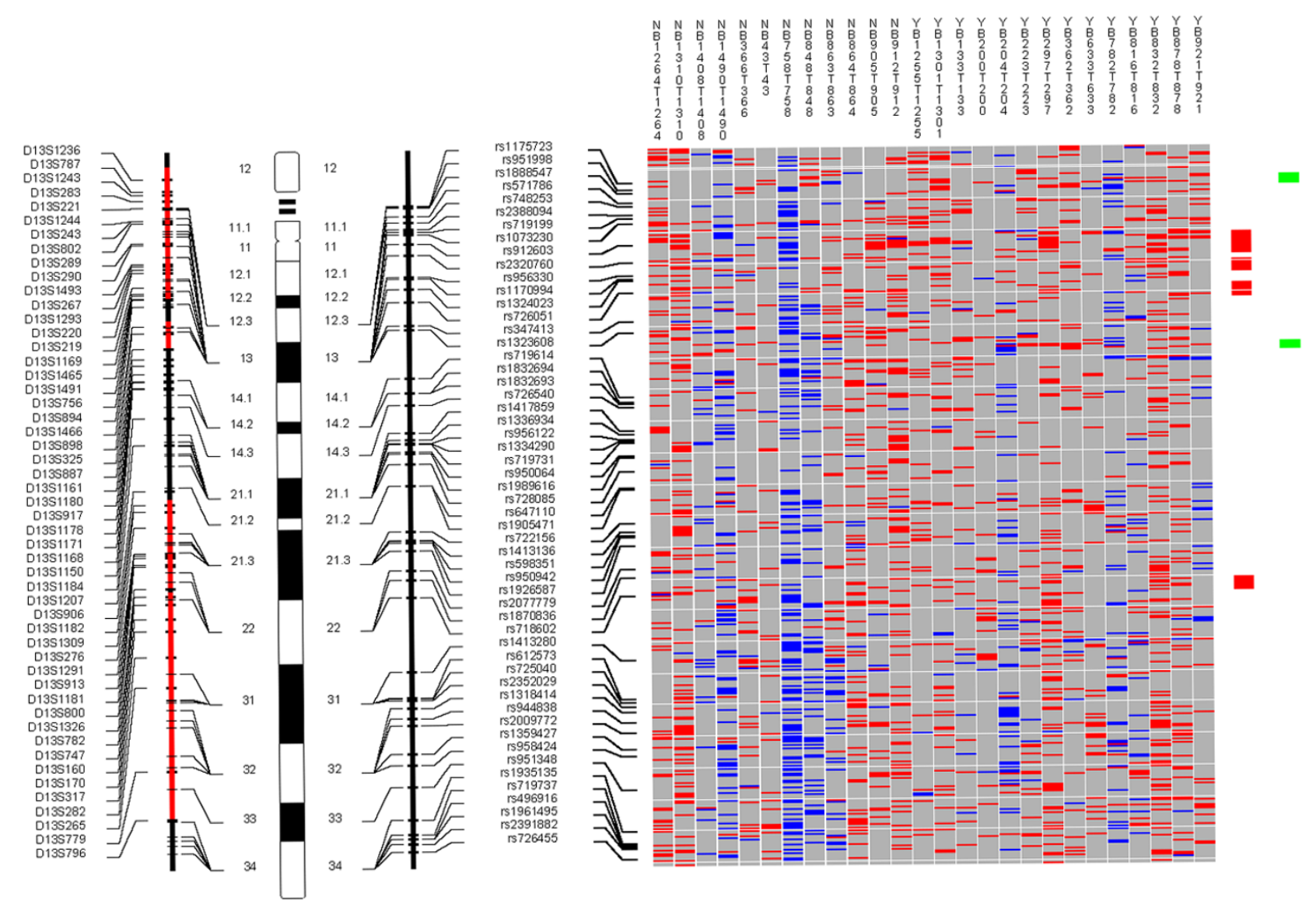

\section{Figure 2}

Chromosome 13. Each column in the picture represents an individual case and shows genotyping in germ-line DNA and matched micro-dissected tumor; LOH is shown in red, retention in blue, and homozygous or "no call" in grey. B indicates blood DNA and T indicates tumor DNA (from matched, micro-dissected sample). To the left of the picture, columns show (from left to right): microsatellite markers, cartoon of the chromosome, and SNPs examined in the $10 \mathrm{~K}$ SNP chip. To the right of the picture, red bars show deletion regions (as defined from our conservative "LOH/Model A"), blue bars show regions with CNA losses (from CNAT), and green bars show regions with CNA gains (from CNAT).

This report is the first comprehensive genome-wide analysis of chromosomal imbalance (LOH and CNA) in ESCC, and the knowledge gained from this analysis will enable the development of improved strategies to prevent, diagnose, and treat ESCC patients in the future.

\section{Conclusion}

The Affymetrix $10 \mathrm{~K}$ SNP chip is a valid platform to integrate analyses of loss of heterozygosity and copy number alterations. The comprehensive knowledge gained from this analysis will enable improved strategies to prevent, diagnose, and treat esophageal squamous cell carcinoma.

\section{Methods}

\section{Patient selection}

This study was approved by the Institutional Review Boards of the Shanxi Cancer Hospital and the US National
Cancer Institute. Patients diagnosed with ESCC between 1998 and 2000 in the Shanxi Cancer Hospital in Taiyuan, Shanxi Province, People's Republic of China, and considered candidates for curative surgical resection were identified and recruited to participate in this study. None of the patients had prior therapy and Shanxi was the ancestral home for all. After obtaining informed consent, patients were interviewed to obtain information on demographic, clinical, and cancer lifestyle risk factors (smoking, alcohol drinking, and detailed family history of cancer). All patients were followed to ascertain survival status through 2003.

\section{Biologic specimen collection and processing}

Ten milliliters of venous blood was taken from each patient prior to surgery and germ-line DNA was extracted and purified using standard methods. Tumor and adja- 

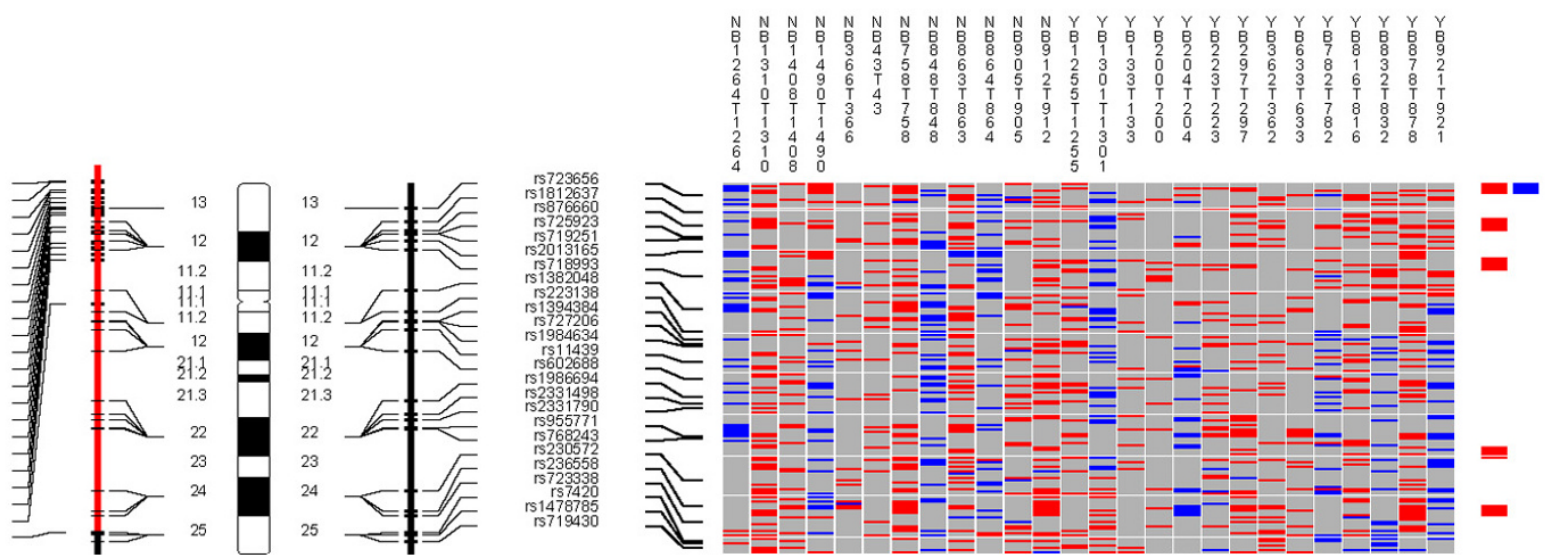

\section{Figure 3}

Chromosome 17. Each column in the picture represents an individual case and shows genotyping in germ-line DNA and matched micro-dissected tumor; LOH is shown in red, retention in blue, and homozygous or "no call" in grey. B indicates blood DNA and T indicates tumor DNA (from matched, micro-dissected sample). To the left of the picture, columns show (from left to right): microsatellite markers, cartoon of the chromosome, and SNPs examined in the $10 \mathrm{~K}$ SNP chip. To the right of the picture, red bars show deletion regions (as defined from our conservative "LOH/Model A"), blue bars show regions with CNA losses (from CNAT), and green bars show regions with CNA gains (from CNAT).

cent normal tissue obtained during surgery were either fixed in ethanol and embedded in paraffin, or snap frozen in liquid nitrogen and stored in a freezer at $-80^{\circ} \mathrm{C}$ until used. Slides were stained with H\&E to distinguish tumor from normal epithelium, and tumor cells were micro-dissected under light microscopy using either laser capture micro-dissection (LCM) (for paraffin-embedded samples) or manual dissection (for frozen samples). All micro-dissections were performed by a pathologist (NL) and a trained post-doctoral fellow (HS). Extraction of LCM DNA was previously described $[17,23]$. Extraction of manually micro-dissected DNA followed the protocol from the Puregene DNA Purification Tissue Kit (Cat Number D7000A, Gentra Systems, Inc., Minneapolis, MN 55441, USA).

It is well known that using pure tumor DNA obtained by micro-dissection is key to successfully detecting chromosomal changes such as $\mathrm{LOH}$ and CNA. However, the $10 \mathrm{~K}$ chip requires amplification of DNA fragments up to $1 \mathrm{~Kb}$, a particularly challenging task. It is usually difficult to obtain a high yield of DNA from alcohol- or formalinfixed tissues, especially when using micro-dissection. In our study, the SNP call rates were much lower in microdissected tumor DNA from alcohol-fixed tissue than from frozen tissue (data not shown). Although the isolation of tumor DNA from ground tissue using Trizol yielded higher genotype call rates, we think that it is more important to identify LOH and CNA regions than to simply obtain higher genotype call rates. Thus, the best overall genomic characterization results can be expected from the use of micro-dissected frozen tissue.

\section{Affymetrix GeneChip Mapping $10 \mathrm{~K}$ array}

The $10 \mathrm{~K} \mathrm{SNP}$ array provides comprehensive coverage of the genome for genotyping studies. Each array contained 11,555 bi-allelic polymorphic SNPs randomly distributed throughout the genome, except for the $\mathrm{Y}$ chromosome. The median physical distance between SNPs is approximately $105 \mathrm{~kb}$, and the mean distance between SNPs is $210 \mathrm{~kb}$. The average heterozygosity for these SNPs is 0.37 , with an average minor allele frequency of 0.25 . The algorithm used to make genotype calls was previously described by Affymetrix [24,25]. DNA samples were assayed according to the protocol (GeneChip Mapping Assay manual) supplied by Affymetrix, Inc. (Santa Clara, CA) as previously described $[25,26]$. The $10 \mathrm{~K} \mathrm{SNP}$ arrays were scanned with the Affymetrix GeneChip Scanner 3000 using GeneChip Operating System 1.2 (GCOS) (Affymetrix). Data files were generated automatically. Genotype assignments (ie, calls) were made automatically by GeneChip DNA Analysis Software 3.0 (GDAS) (Affymetrix). The genetic map used in the analysis was obtained from GeneChip Mapping 10 K library files: Mapping 10K_Xba131. "Signal Detection Rate" is the percentage of SNPs that passed the discrimination filter. "Call Rate" is the percentage of SNPs called on the array. Genotype calls are defined as $\mathrm{AA}, \mathrm{AB}$, or $\mathrm{BB}$; "no call" means the 

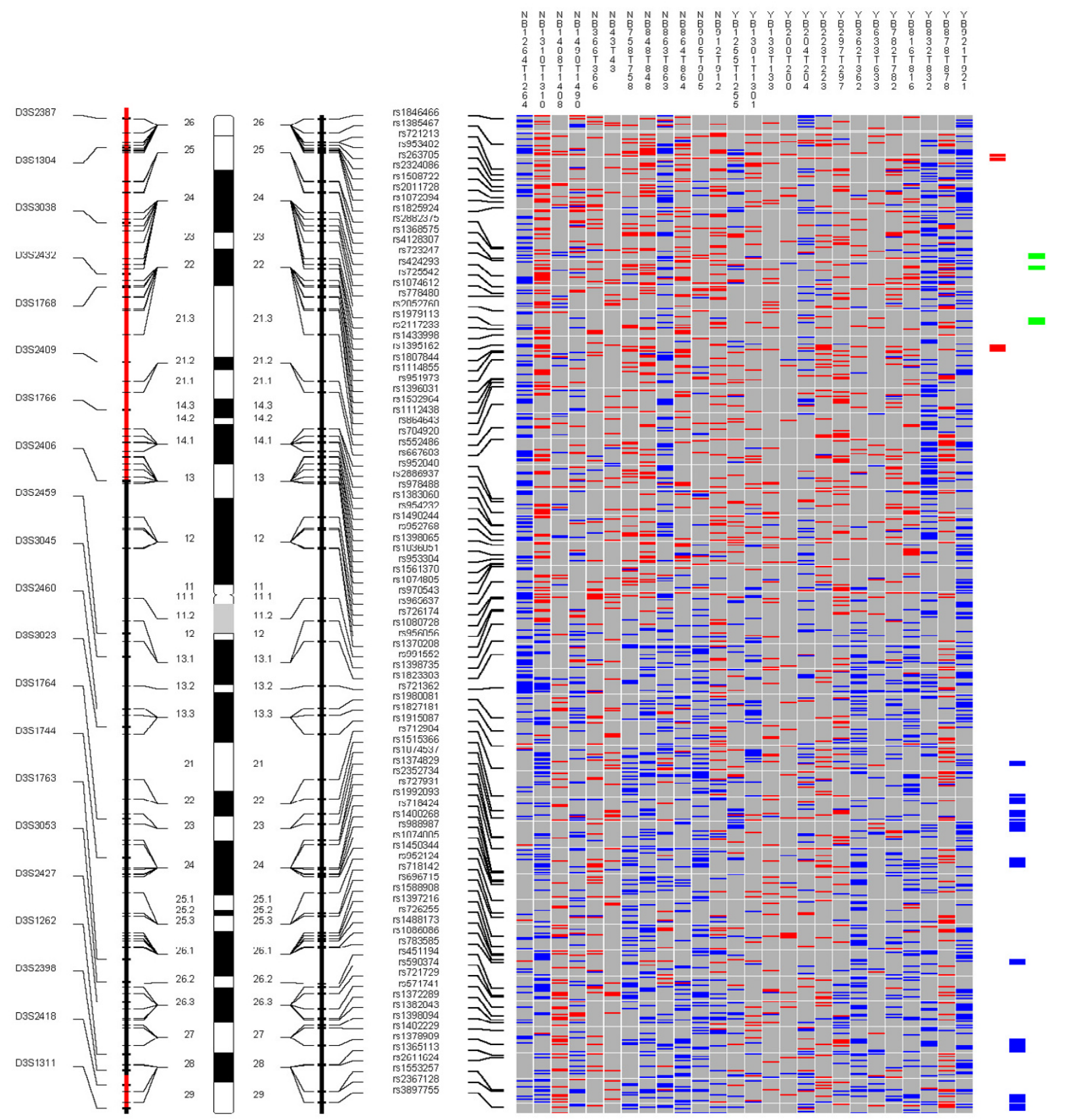

\section{Figure 4}

Chromosome 3. Each column in the picture represents an individual case and shows genotyping in germ-line DNA and matched micro-dissected tumor; LOH is shown in red, retention in blue, and homozygous or "no call" in grey. B indicates blood DNA and T indicates tumor DNA (from matched, micro-dissected sample). To the left of the picture, columns show (from left to right): microsatellite markers, cartoon of the chromosome, and SNPs examined in the $10 \mathrm{~K}$ SNP chip. To the right of the picture, red bars show deletion regions (as defined from our conservative "LOH/Model A"), blue bars show regions with CNA losses (from CNAT), and green bars show regions with CNA gains (from CNAT). 

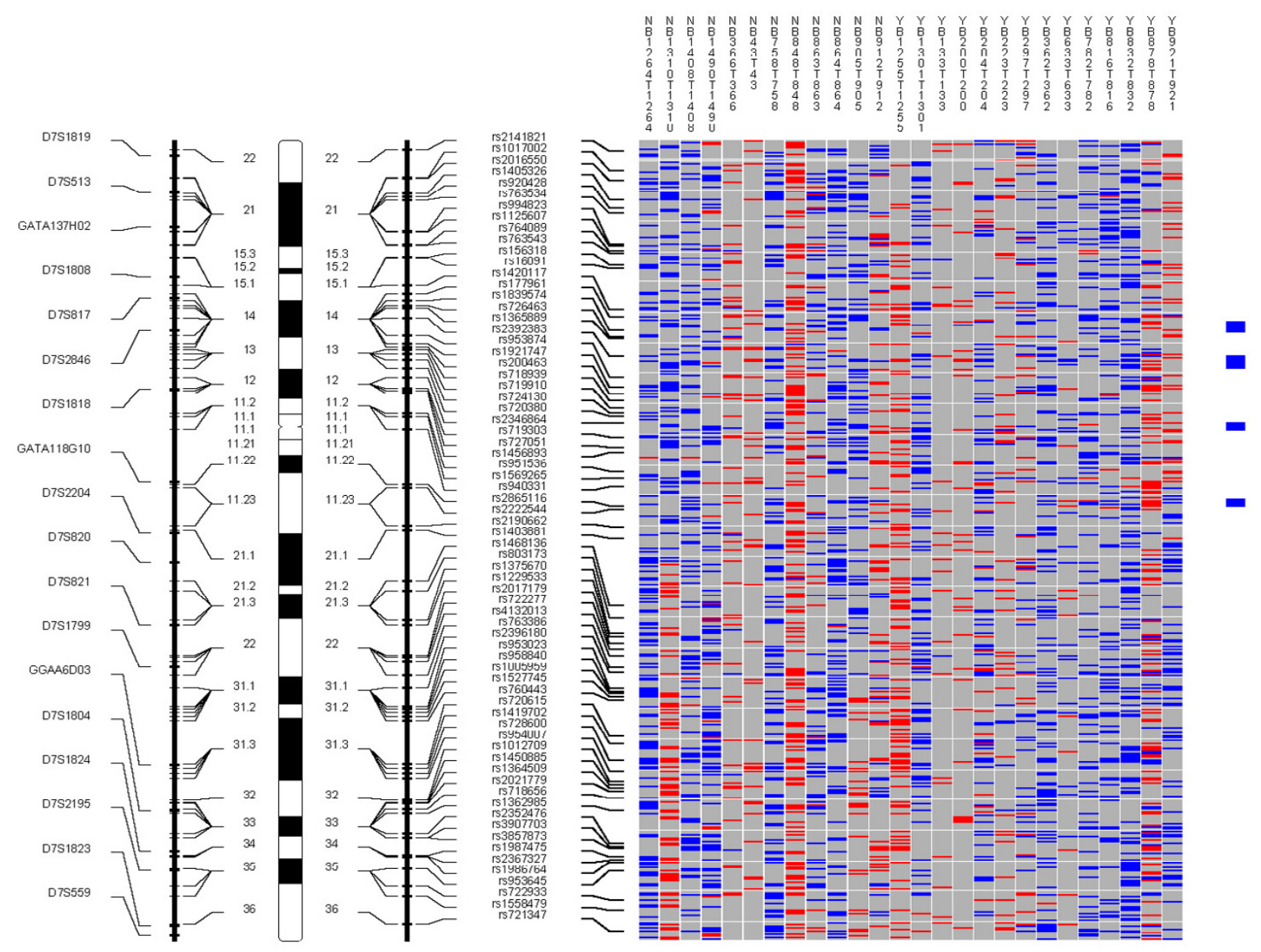

\section{Figure 5}

Chromosome 7. Each column in the picture represents an individual case and shows genotyping in germ-line DNA and matched micro-dissected tumor; LOH is shown in red, retention in blue, and homozygous or "no call" in grey. B indicates blood DNA and T indicates tumor DNA (from matched, micro-dissected sample). To the left of the picture, columns show (from left to right): microsatellite markers, cartoon of the chromosome, and SNPs examined in the $10 \mathrm{~K}$ SNP chip. To the right of the picture, red bars show deletion regions (as defined from our conservative "LOH/Model A"), blue bars show regions with CNA losses (from CNAT), and green bars show regions with CNA gains (from CNAT).

SNP for that sample did not pass the discrimination filter and was excluded from further evaluation in the present study.

\section{Data analysis}

Since patient-matched normal DNA is not always available as a reference for high-resolution allelotyping, we evaluated LOH using two different methods: first, we used patient-matched normal DNA as the reference (the traditional approach); and second, we assessed whether it was possible to instead use a pool of normal control samples as the reference, as is done with the chromosome Copy
Number Analysis Tool 2.0 software (CNAT) from Affymetrix.

In the first method, LOH was defined in a traditional manner as a change in genotyping call from heterozygosity $(\mathrm{AB})$ in the germ-line DNA, to homozygosity (AA or $\mathrm{BB}$ ) in the matched micro-dissected tumor DNA (all calls from GDAS). In the second method, $\mathrm{LOH}$ was also defined as a change in genotyping from "normal" to tumor, however, "normal" here was defined based on data already present in the Affymetrix CNAT software from prior testing of 100 ethnically-diverse normal refer- 

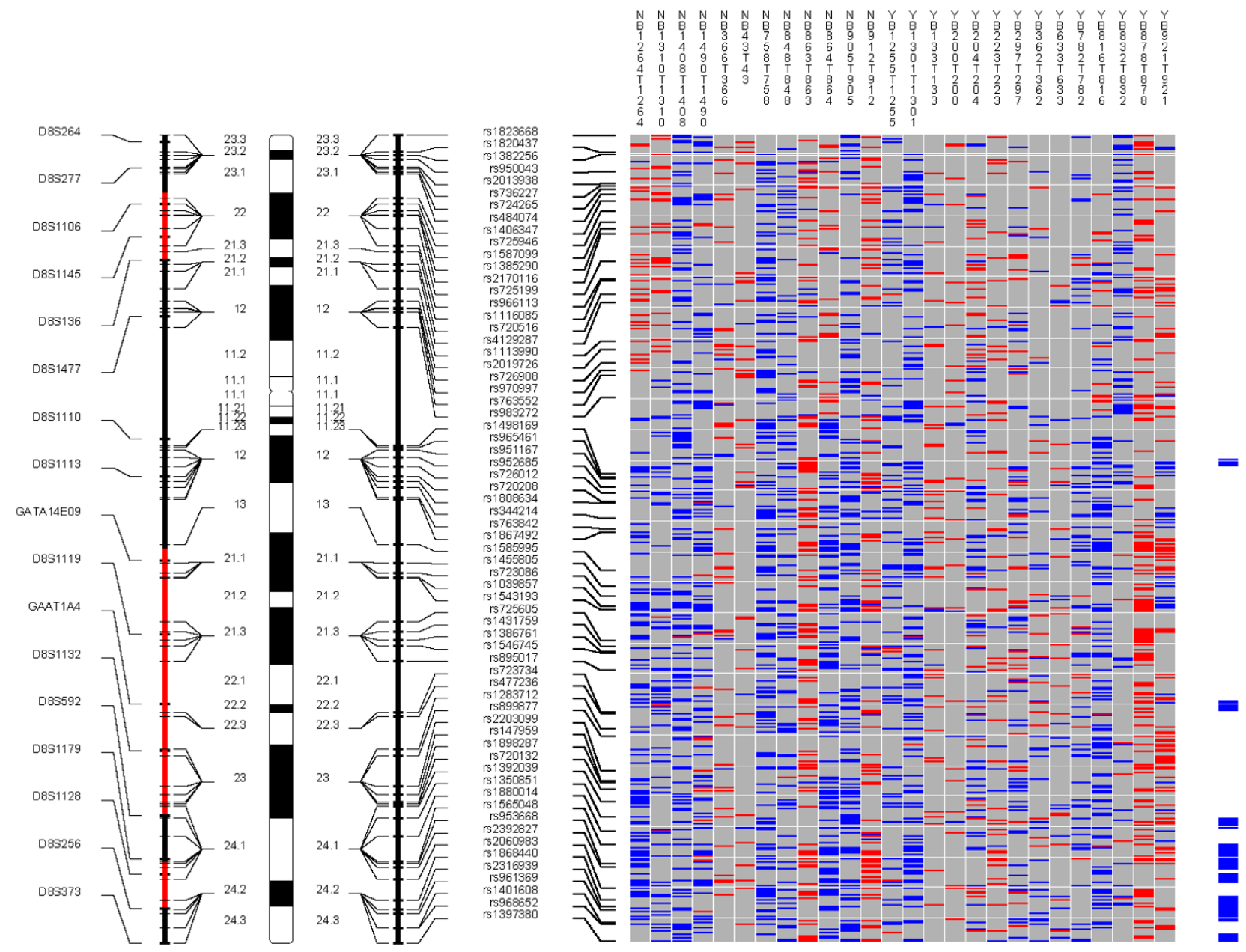

\section{Figure 6}

Chromosome 8. Each column in the picture represents an individual case and shows genotyping in germ-line DNA and matched micro-dissected tumor; LOH is shown in red, retention in blue, and homozygous or "no call" in grey. B indicates blood DNA and T indicates tumor DNA (from matched, micro-dissected sample). To the left of the picture, columns show (from left to right): microsatellite markers, cartoon of the chromosome, and SNPs examined in the $10 \mathrm{~K}$ SNP chip. To the right of the picture, red bars show deletion regions (as defined from our conservative "LOH/Model A"), blue bars show regions with CNA losses (from CNAT), and green bars show regions with CNA gains (from CNAT).

ence subjects [27]. LOH in the second method was based on a comparison of a track of contiguous SNPs in tumor to the analogous track of contiguous SNPs in the "normal" population DNA. Since the "normal" DNA here includes not just one but 100 individuals, the state of these SNPs (ie, whether they are heterozygous or homozygous) was inferred statistically as a likelihood estimation with confidence calculated from a binomial distribution of the observed state of these SNPs in this normal population. A contiguous run of homozygous SNPs in tumor where these SNPs are heterozygous in the "control" suggests LOH in the region spanning the SNPs. Hence, no germ-line DNA data from cases was used for this second analysis. We refer to this $\mathrm{LOH}$ as "cLOH" to distinguish it from our more traditional analysis approach using paired normal and tumor samples and to indicate that it utilized a common control pool of normal DNA generated by CNAT. The threshold for statistical significance used in CNAT was $P \leq 10^{-6}$ as recommended by Affymetrix [27].

We combined the LOH results from a cluster of SNPs in a genetic locus to define a deletion region. We defined these deletion regions in several ways to permit comparison with the existing scientific literature as well as to make comparisons within our own study using different refer- 
Table 7: Regions with copy number alteration loss from CNAT

\begin{tabular}{cccc}
\hline Chr arm & No. CNA loss regions in each chr arm & Cytoband(s) & Total no. SNPs in each chr arm \\
\hline $1 p$ & 1 & $|p| 3.3$ & 5 \\
$3 p$ & 3 & $3 p 243 p 25-p 24.33 p 25$ & 19 \\
$4 q$ & 1 & $4 q 28$ & 5 \\
$5 q$ & 2 & $5 q|4-q| 55 q 33$ & 23 \\
$9 p$ & 1 & $9 p 21.3$ & 8 \\
$10 p$ & 1 & $|0 p| 2-p \mid 2.1$ & 7 \\
$\mid 1 p$ & 1 & ||$p \mid 5.5$ & 5 \\
$\mid 1 q$ & 2 & $|3 q| 2.2-q|2||3 q| 4$ & 10 \\
$\mid 3 q$ & 2 & $18 q 22$ & 14 \\
$18 q$ & 1 & Total no. SNPs & 102 \\
\hline
\end{tabular}

ence groups as noted above. We first used a definition that permitted comparisons with most of the existing published literature. We constrained the SNPs we considered here to require that: (i) SNPs have a call in $\geq 50 \%$ of the normal DNA samples; (ii) there be a minimum of three informative (heterozygous) normal samples; and (iii) the SNPs be mappable to NCBI Build 35.1. Non-random allelic loss was defined as $\mathrm{LOH}$ frequency $\geq 50 \%$ at a given locus, while random allelic loss represented $\mathrm{LOH}$ frequency $<50 \%$ at a locus. Using these constraints for the SNPs evaluated, we defined deletion regions very conservatively by requiring that the deletion regions have five or more contiguous SNPs which showed $\geq 75 \%$ LOH. Uninformative SNPs in the regions of $\mathrm{LOH}$ were excluded from consideration in this analysis. Thus, a region of LOH separated from a second region of $\mathrm{LOH}$ by only uninformative SNPs would be combined into one large LOH region. We labeled this conservative, traditional approach " $\mathrm{LOH} /$ Model A".

The second approach we took (labeled "LOH/Model B") was very similar to $\mathrm{LOH} /$ Model $\mathrm{A}$ in that we used the same constraints on the SNPs noted above, but we were less conservative in our requirement for the percent of the deletion region which showed LOH - only $\geq 50 \% \mathrm{LOH}$ frequency (instead of $\geq 75 \%$ ) among the SNPs was required to be classified as a deletion region. To enable comparability with data from the cLOH approach

Table 8: Regions with copy number alteration gain from CNAT

\begin{tabular}{|c|c|c|c|}
\hline Chr arm & $\begin{array}{l}\text { No. CNA gain regions in } \\
\text { each chr arm }\end{array}$ & Cytoband(s) & $\begin{array}{l}\text { Total no. SNPs in } \\
\text { each chr arm }\end{array}$ \\
\hline Ip & I & $1 \mathrm{p} 36.13$ & 5 \\
\hline $\mathrm{lq}$ & I & $|q 2| .3-|q 2|$ & 8 \\
\hline $2 p$ & I & $2 p 14$ & 6 \\
\hline $2 q$ & 2 & $2 q 11.22 q 21$ & 15 \\
\hline $3 q$ & 8 & $3 q 21-q 223 q 22-q 233 q 23(2) 3 q 243 q 26.13 q 273 q 28$ & 69 \\
\hline $5 p$ & 2 & $5 p \mid 5.2(2)$ & 14 \\
\hline $5 q$ & I & $5 q 11.2$ & 5 \\
\hline $6 p$ & I & 6p25.3-p24 & 8 \\
\hline $7 p$ & 3 & $7 p \mid 4(2) 7 p 12$ & 24 \\
\hline $7 q$ & I & $7 q|1.21-q| 1.22$ & 5 \\
\hline $8 q$ & 7 & $8 q 24.2$ (2) 8q24.1 (3) 8q22 8q। I.2 & 66 \\
\hline $9 q$ & I & $9 q 31-q 31.3$ & 7 \\
\hline $14 q$ & 2 & $|4 q 2|-q 22 \mid 4 q 22-q 23$ & 16 \\
\hline $17 p$ & I & $17 p|3.1-p| 3.2$ & 7 \\
\hline $18 p$ & I & $|8 p| 1.3 \mid$ & 8 \\
\hline $20 p$ & I & $20 p|I . I-q| I . I$ & 13 \\
\hline $22 q$ & 2 & $22 q 12.122 q 13.1$ & 11 \\
\hline no. gain regions & 36 & Total no. SNPs & 287 \\
\hline
\end{tabular}




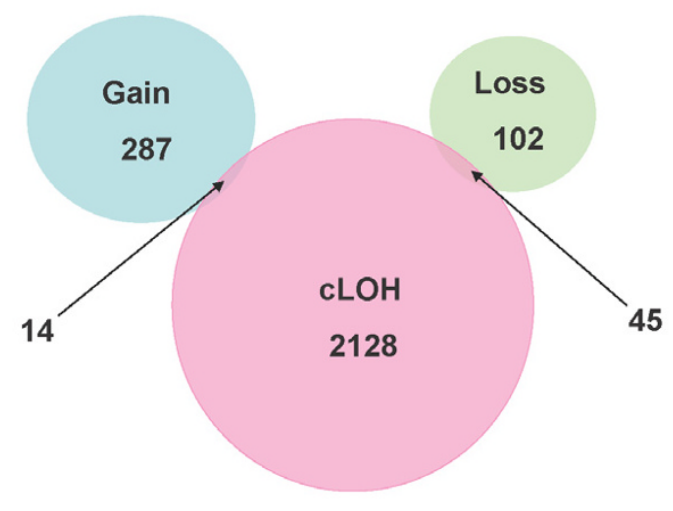

Figure 7

Comparison of SNPs with cLOH (from our less conservative "cLOH/Model B") and CNAs (from CNAT software using pooled DNA from normal controls).

described above, we also adopted different guidance regarding how we treated homozygous SNPs in these putative LOH regions defined by the traditional approach. In CNAT, a contiguous track of homozygous SNPs are required to designate a region as having $\mathrm{LOH}$. When a homozygous SNP is located between two SNPs where one or both of the adjacent SNPs showed retention of heterozygosity, the homozygous SNP was considered retained. Otherwise, it was treated as $\mathrm{LOH}$.

We also developed two models using exclusively data from the CLOH approach with the CNAT-generated pooled controls. The first used the conservative definition described above for $\mathrm{LOH} /$ Model $\mathrm{A}$ of $\mathrm{a} \geq 75 \% \mathrm{LOH}$ requirement to declare a deletion region, and also treated homozygous SNPs in deletion regions in accord with the CNAT algorithm described above; we termed this "cLOH/ Model A". Although the level of $\mathrm{LOH}$ required is the same for $\mathrm{LOH} /$ Model A and cLOH/Model A, direct comparisons between them are not possible because of the different algorithms used to treat uninformative SNPs in deletion regions. The second approached loosened the $\mathrm{LOH}$ requirement to $\geq 50 \%$ to declare a deletion region (as with LOH/Model B above), also used the CNAT algorithm for homozygous SNP calls in deletion regions, and was termed "cLOH/Model B".

Individual SNP copy numbers and chromosomal regions with gains or losses were also determined by evaluation with CNAT based on the SNP hybridization signal intensity data from the experimental sample relative to intensity distributions derived from the previously described reference set containing over 100 normal individuals [27]. $P$-values were $\log _{10}$-transformed and plotted along the corresponding chromosome; values were considered significant at $P \leq 10^{-6}$.

We further defined CNA-gain regions as regions where five or more contiguous SNPs showed copy number gain in at least $50 \%$ of cases, and the $P$-value for the difference from the reference was $\leq 10^{-6}$. Similarly, CNA-loss regions were defined as regions where five or more contiguous SNPs showed copy number loss in at least $50 \%$ of cases, and the $P$-value for the difference from the reference was $\leq 10^{-6}$.

\section{Abbreviations}

SNP, single nucleotide polymorphism; ESCC, esophageal squamous cell carcinoma; LOH, loss of heterozygosity; CNA, copy number alteration; LCM, laser-capture microdissection; CNAT, copy number analysis tool; GCOS, GeneChip Operating System; GDAS, GeneChip DNA Analysis Software; cLOH, LOH determined by comparing patient tumor DNA with common control pool of DNA; NCBI, National Center for Biotechnology Information

\section{Authors' contributions}

$\mathrm{NH}$ conceived of study, oversaw laboratory and statistical analysis, and drafted the manuscript. CW, NL, and HS performed the laboratory analyses and conducted initial statistical analyses. YH and HHY directed final statistical analyses. L-HK and Q-HW oversaw the data and sample collection procedures for the study. AMG conceived of the study, participated in statistical analyses, and revised the manuscript. KHB provided general statistical and scientific guidance for the study. ME-B conceived of the study, aided in interpretation of the data, and revised the manuscript. PRT conceived of the study, oversaw laboratory and statistical analyses, revised the manuscript, and obtained funding. MPL conceived of the study, oversaw statistical analyses, and revised the manuscript. All authors read and approved the final manuscript.

\section{Additional material}

\section{Additional File 1}

Additional tables. Additional tables show more details of deletion regions and copy number alteration loss and gain regions. ADDITIONAL TABLE 1. Deletion regions from the less conservative " $\mathrm{LOH} /$ Model B" (detailed). ADDITIONAL TABLE 2. Deletion regions from the less conservative "cLOH/Model B" (detailed). ADDITIONAL TABLE 3. Copy number alteration loss regions from CNAT (detailed). ADDITIONAL TABLE 4. Copy number alteration gain regions from CNAT (detailed).

Click here for file

[http://www.biomedcentral.com/content/supplementary/14712164-7-299-S1.doc] 


\section{Acknowledgements}

This research was supported by the Intramural Research Program of the $\mathrm{NIH}$, the National Cancer Institute, the Center for Cancer Research, and the Division of Cancer Epidemiology and Genetics.

\section{References}

I. Maris JM, Hii G, Gelfand CA, Varde S, White PS, Rappaport E, Surrey $S$, Fortina P: Region-specific detection of neuroblastoma loss of heterozygosity at multiple loci simultaneously using a SNP-based tag-array platform. Genome Res 2005, I5: I I68-I I 76.

2. Phillips MS, Lawrence R, Sachidanandam R, Morris AP, Balding DJ, Donaldson MA, Studebaker JF, Ankener WM, Alfisi SV, Kuo FS, Camisa AL, Pazorov V, Scott KE, Carey BJ, Faith J, Katari G, Bhatti HA, Cyr JM, Derohannessian V, Elosua C, Forman AM, Grecco NM, Hock CR, Kuebler JM, Lathrop JA, Mockler MA, Nachtman EP, Restine SL, Varde SA, Hozza MJ, Gelfand CA, Broxholme J, Abecasis GR, Boyce-Jacino MT, Cardon LR: Chromosome-wide distribution of haplotype blocks and the role of recombination hot spots. Nat Genet 2003, 33:382-387.

3. Zhao X, Li C, Paez JG, Chin K, Janne PA, Chen TH, Girard L, Minna J, Christiani D, Leo C, Gray JW, Sellers WR, Meyerson M: An integrated view of copy number and allelic alterations in the cancer genome using single nucleotide polymorphism arrays. Cancer Res 2004, 64:3060-307I.

4. Janne PA, Li C, Zhao X, Girard L, Chen TH, Minna J, Christiani DC Johnson BE, Meyerson M: High-resolution single-nucleotide polymorphism array and clustering analysis of loss of heterozygosity in human lung cancer cell lines. Oncogene 2004, 23:2716-2726.

5. Wong KK, Tsang YT, Shen J, Cheng RS, Chang YM, Man TK, Lau CC: Allelic imbalance analysis by high-density single-nucleotide polymorphic allele (SNP) array with whole genome amplified DNA. Nucleic Acids Res 2004, 32:e69.

6. Sellick GS, Webb EL, Allinson R, Matutes E, Dyer MJ, Jonsson V, Langerak AW, Mauro FR, Fuller S, Wiley J, Lyttelton M, Callea V, Yuille M, Catovsky D, Houlston RS: A high-density SNP genomewide linkage scan for chronic lymphocytic leukemia-susceptibility loci. Am J Hum Genet 2005, 77:420-429.

7. Middleton FA, Pato MT, Gentile KL, Morley CP, Zhao X, Eisener AF, Brown A, Petryshen TL, Kirby AN, Medeiros H, Carvalho C, Macedo A, Dourado A, Coelho I, Valente J, Soares MJ, Ferreira CP, Lei M, Azevedo MH, Kennedy JL, Daly MJ, Sklar P, Pato CN: Genomewide linkage analysis of bipolar disorder by use of a high-density single-nucleotide-polymorphism (SNP) genotyping assay: a comparison with microsatellite marker assays and finding of significant linkage to chromosome 6q22. Am J Hum Genet 2004, 74:886-897.

8. Zhou X, Mok SC, Chen Z, Li Y, Wong DT: Concurrent analysis of loss of heterozygosity (LOH) and copy number abnormality (CNA) for oral premalignancy progression using the Affymetrix IOK SNP mapping array. Hum Genet 2004, I I 5:327-330.

9. Herr A, Grutzmann R, Matthaei A, Artelt J, Schrock E, Rump A, Pilarsky C: High-resolution analysis of chromosomal imbalances using the Affymetrix IOK SNP genotyping chip. Genomics 2005, 85:392-400.

10. Koed K, Wiuf C, Christensen LL, Wikman FP, Zieger K, Moller K, von der $\mathrm{MH}$, Orntoft TF: High-density single nucleotide polymorphism array defines novel stage and location-dependent allelic imbalances in human bladder tumors. Cancer Res 2005 , 65:34-45.

II. Irving JA, Bloodworth L, Bown NP, Case MC, Hogarth LA, Hall AG: Loss of heterozygosity in childhood acute lymphoblastic leukemia detected by genome-wide microarray single nucleotide polymorphism analysis. Cancer Res 2005, 65:3053-3058.

12. Teh MT, Blaydon D, Chaplin T, Foot NJ, Skoulakis S, Raghavan M, Harwood CA, Proby CM, Philpott MP, Young BD, Kelsell DP: Genomewide single nucleotide polymorphism microarray mapping in basal cell carcinomas unveils uniparental disomy as a key somatic event. Cancer Res 2005, 65:8597-8603.

13. Li JY: Epidemiology of esophageal cancer in China. Natl Cancer Inst Monogr 1982, 62:1 I3-120.

14. Qiao YL, Hou J, Yang L, He YT, Liu YY, Li LD, Li SS, Lian SY, Dong ZW: [The trends and preventive strategies of esophageal cancer in high-risk areas of Taihang Mountains, China] Zhongguo Yi Xue Ke Xue Yuan Xue Bao 2001, 23:10-14.
15. Hu N, Roth MJ, Polymeropolous M, Tang ZZ, Emmert-Buck MR Wang QH, Goldstein AM, Feng SS, Dawsey SM, Ding T, Zhuang ZP, Han XY, Ried T, Giffen C, Taylor PR: Identification of novel regions of allelic loss from a genomewide scan of esophageal squamous-cell carcinoma in a high-risk Chinese population. Genes Chromosomes Cancer 2000, 27:217-228.

16. Roth MJ, Hu N, Emmert-Buck MR, Wang QH, Dawsey SM, Li G, Guo WJ, Zhang YZ, Taylor PR: Genetic progression and heterogeneity associated with the development of esophageal squamous cell carcinoma 47I. Cancer Res 200I, 6 I:4098-4 I04.

17. Huang J, Hu N, Goldstein AM, Emmert-Buck MR, Tang ZZ, Roth MJ, Wang QH, Dawsey SM, Han XY, Ding T, Li G, Giffen C, Taylor PR: High frequency allelic loss on chromosome I7p I3.3-p I I.I in esophageal squamous cell carcinomas from a high incidence area in northern China. Carcinogenesis 2000, 21:2019-2026.

18. Hu N, Huang J, Emmert-Buck MR, Tang ZZ, Roth MJ, Wang C, Dawsey SM, Li G, Li WJ, Wang QH, Han XY, Ding T, Giffen C, Goldstein AM, Taylor PR: Frequent inactivation of the TP53 gene in esophageal squamous cell carcinoma from a high-risk population in China. Clin Cancer Res 200I, 7:883-89I.

19. Lo HS, Hu N, Gere S, Lu N, Su H, Goldstein AM, Taylor PR, Lee MP: Identification of somatic mutations of the RNF6 gene in human esophageal squamous cell carcinoma. Cancer Res 2002 , 62:4191-4193.

20. Hu N, Li WJ, Su H, Wang C, Goldstein AM, Albert PS, Emmert-Buck MR, Kong LH, Roth MJ, Dawsey SM, He LJ, Cao SF, Ding T, Giffen C, Taylor PR: Common genetic variants of TP53 and BRCA2 in esophageal cancer patients and healthy individuals from low and high risk areas of northern China. Cancer Detect Prev 2003, 27: $132-138$

2I. Hu N, Roth MJ, Emmert-Buck MR, Tang ZZ, Polymeropolous M, Wang QH, Goldstein AM, Han XY, Dawsey SM, Ding T, Giffen C, Taylor PR: Allelic loss in esophageal squamous cell carcinoma patients with and without family history of upper gastrointestinal tract cancer. Clin Cancer Res 1999, 5:3476-3482.

22. Hu N, Su H, Li WJ, Giffen C, Goldstein AM, Hu Y, Wang C, Roth MJ, Li G, Dawsey SM, Xu Y, Taylor PR, Emmert-Buck MR: Allelotyping of esophageal squamous-cell carcinoma on chromosome I3 defines deletions related to family history. Genes Chromosomes Cancer 2005, 44:27|-278.

23. Emmert-Buck MR, Bonner RF, Smith PD, Chuaqui RF, Zhuang Z, Goldstein SR, Weiss RA, Liotta LA: Laser capture microdissection. Science 1996, 274:998-1001.

24. Kennedy GC, Matsuzaki H, Dong S, Liu WM, Huang J, Liu G, Su X, Cao M, Chen W, Zhang J, Liu W, Yang G, Di X, Ryder T, He Z, Surti U, Phillips MS, Boyce-Jacino MT, Fodor SP, Jones KW: Large-scale genotyping of complex DNA. Nat Biotechnol 2003, 2 I : I 233- I 237.

25. Liu WM, Di X, Yang G, Matsuzaki H, Huang J, Mei R, Ryder TB, Webster TA, Dong S, Liu G, Jones KW, Kennedy GC, Kulp D: Algorithms for large-scale genotyping microarrays. Bioinformatics 2003, 19:2397-2403.

26. Hu N, Wang C, Hu Y, Yang HH, Giffen C, Tang ZZ, Han XY, Goldstein AM, Emmert-Buck MR, Buetow KH, Taylor PR, Lee MP: Genome-wide association study in esophageal cancer using GeneChip mapping I OK array. Cancer Res 2005, 65:2542-2546.

27. Huang J, Wei W, Zhang J, Liu G, Bignell GR, Stratton MR, Futreal PA, Wooster R, Jones KW, Shapero MH: Whole genome DNA copy number changes identified by high density oligonucleotide arrays. Hum Genomics 2004, I:287-299. 